2016

Education for Sustainable Development:

a movement towards pedagogies of

civic compassion

\title{
Warwick, Paul
}

http://hdl.handle.net/10026.1/8148

10.15730/forum.2016.58.3.407

FORUM

Lawrence and Wishart

All content in PEARL is protected by copyright law. Author manuscripts are made available in accordance with publisher policies. Please cite only the published version using the details provided on the item record or document. In the absence of an open licence (e.g. Creative Commons), permissions for further reuse of content should be sought from the publisher or author. 


\title{
Education for Sustainable Development: a movement towards pedagogies of civic compassion
}

\section{Paul Warwick}

\section{Plymouth University, UK.}

\begin{abstract}
This paper explores the moral imperative for a renewed vision of schooling in the $21^{\text {st }}$ century, from the standpoint of Education for Sustainable Development (ESD). ESD, advocates for teaching and learning spaces underpinned by civic compassion in the sense of 'an active concern for well-being'. This love based paradigm of education seeks to expand the horizons of our compassion for others; calling for an education system that takes into account the need for biosphere, spatial and temporal dimensions of care for the common good. This vision of education is firstly outlined and then practically explored through an example of ESD innovation in practice; a participatory education programme in sustainability leadership with students from primary, secondary, and post 16 educational settings. ESD is put forward as offering a vital and broad opportunity for the advancement of social justice in education, supporting the creation of kinder learning spaces that position educators as facilitators of civically engaged compassionate learning.
\end{abstract}

\section{Introduction}

Children and young people are growing up in the midst of multiple points of planetary crisis including climate change, extreme poverty, biodiversity loss, widening socio-economic inequality, and the weakening of oceanic and terrestrial ecosystems (UNESCO 2015). Such threats to our well-being are manifold in nature and interconnected in form. The complexity of these challenges means it is extremely difficult for us to fathom and predict their future consequences, contributing to ever-increasing narratives of uncertainty and risk.

Since the 1970s alternative models of development have advocated a greater prioritisation of human well-being but with an awareness of ecological limits and planetary boundaries (Zusman et al 2015). In 1987 the concept of sustainable development was popularised by the World Commission on Environment and Development and their report Our Common Future (WCED 1987). This defined sustainable development as:

Development which meets the needs of the present without compromising the ability of future generations to meet their own needs. (WCED 1987:43)

In line with the aims of sustainable development, significant progress has been made towards 'well-being for all' targets, as defined by the Millennium Development Goals, for example, yet a myriad of global challenges remain prevalent. Recognising there is great work still to be done the United Nations has launched the Sustainable Development Goals (SDGs), a series of 17 social justice and environmental stewardship targets to be achieved worldwide by 2030 (United Nations 2015). These SDGs are ambitious and far-reaching. For example, they call not for a mere percentage reduction in levels of poverty, but instead for an end to poverty in all its forms everywhere by 2030. Achieving these goals requires nothing short of a compassionate societal transformation and education is increasingly being identified as a key agent in this process of change (IGES 2015). But crucially, it is education of a certain kind 
that is being advocated for, rather than simply a more efficient and 'for all' worldwide delivery of the current dominant form of neoliberal education. Education in itself needs to be transformed if it is to contribute to this compassionate societal shift (UNESCO 2015).

Scholars such as Stephen Sterling $(2001,2005)$ in the UK and David Orr $(1994,2011)$ in the US, to name but two, have called for a new and sustainable paradigm of education to be pursued, fusing concerns for social justice with those of wise environmental stewardship.

\section{The emergence of Education for Sustainable Development}

The seriousness and prevalence of worldwide sustainability challenges is inspiring an international movement of pioneering educators to pursue a paradigm of Education for Sustainable Development. Its emergence as a global educational reform agenda has been aided by the UN declaring a Decade of ESD between 2005-2014 and subsequently a Global Action Programme for ESD (UNESCO 2014). This Global Action Programme states: 'There is now a growing international recognition of ESD as an integral element of quality education' (UNESCO 2014:9). It calls for a reorientation of education towards sustainable development for all, through five priority areas that include 'empowering and mobilising youth' (UNESCO 2014:22).

Whilst still emerging as an alternative education paradigm, Education for Sustainable Development can be characterised as being underpinned by an ethic of compassionate concern for well-being and the common good (UNESCO 2015). This civic kindness and care for others, I have previously described (Peterson and Warwick 2015) as being extended across three relational dimensions. The first of these is the biosphere, where an active concern for the common good encompasses people and the environment. This ESD dimension invites learners to not only consider their contribution to the well-being of other people but also to other species and the vitality of the very ground upon which all life depends. It very much supports the need for competency development in social justice coupled with systems thinking and ecological literacy. The second relational consideration in ESD is the spatial dimension. This encourages learners to develop an active concern for the common good spanning across place; from the local to the global. It seeks to raise awareness of how through processes of globalisation our lives today are caught up in networks of mutuality and interconnectivity. Alongside encouraging competency development for personal agency in neighbourhood renewal this dimension seeks to draw out qualities of global citizenship. The third relational dimension in ESD is the temporal dimension. This recognises the interconnectivity of life across time inviting learners to consider the well-being needs of future generations and landscapes as well as in the present. This dimension requires the development of anticipatory competencies and futures thinking where preferable futures are envisaged and collaboratively worked towards (Rieckmann 2011).

These relational dimensions to ESD bring into pedagogy an acknowledgement of our interconnectivity and interdependence across species, place and time. Through engaging learners with this extended notion of concern for the common good, ESD is holistic in nature, seeking to draw out from all students a range of compassionate competencies and qualities that encompass knowledge and understanding, skills and values.

\section{Putting Education for Sustainable Development into practice}

Education for Sustainable Development, as expounded by scholars such as Sterling (2001), represents an integrated and systemic approach to the radical transformation of dominant 
educational systems. It is a vision of an alternative system that has implications for the very fabric and form of our educational institutions, encompassing curriculum and pedagogy but also the design and architecture of our campuses and the very culture of our schools. It has implications for the systems of operation, staffing, leadership, relational processes with students, and the interface with the school's community as a whole. Consequently, achieving the maximal potential of ESD in all its fullness is difficult to achieve as it requires manifold educational change. But in the pursuit of putting into practice their transformative educational agenda, Fielding and Moss (2011) provide a useful concept of prefigurative practice. This refers to the importance of educators and students experimenting with reforms in practice that are possible within the context of their existing institutions. Fielding and Moss offer encouragement for educators and students to begin to pragmatically pursue their vision of what could be, to exercise their anticipatory competence, as referred to by Rieckmann (2011), by backcasting from a vision of a preferable educational future and putting in place steps towards this in the here and now of today. In the spirit of prefigurative practice, the Future Leaders Programme represents my own experiment in ESD practice in partnership with a range of teachers and youth workers. The aim of the programme has been to engage students in civic compassion and to learn sustainable development through the process of exercising their sense of agency and collaboratively leading their own sustainability change project. Initially established as the Community Action Team initiative, this educational programme has been run with students in a range of primary and secondary schools as well as post 16 and informal education settings. It has been linked to sustainable development agendas within the formal curriculum through the subject area of Citizenship Education, which is part of the UK National Curriculum, and as an extra-curricular initiative with links to the UK's National Framework for Sustainable Schools (DCSF 2008).

The design of the Future Leaders Programme has drawn in particular from participatory models of how students can actively shape their own learning, such as Hart's (1997) ladder of children's participation (1997) and more recently Fielding's (2011) patterns of partnership typology. It has sought to offer a range of participatory learning opportunities through facilitating three main types of learning space. The first is space for compassionate conversation where through student voice activities staff invite students to enter into dialogic conversations with each other about the sustainability issues that matter most to them and that they have a feeling of compassion towards. In so doing students begin to encounter areas of mutuality and solidarity with each other as well as a lived experience of the diversity of perspectives peers can hold over their well being cares and concerns. Within this space students are viewed as joint authors making decisions collectively with staff and negotiating choices in order to plot the programme's subsequent focus and direction. The second learning space is compassionate enquiry through which students are supported in deepening their understanding of their chosen sustainability issues. This engages students as researchers, encouraging them to seek out different perspectives from those affected by the sustainability issue, or involved in studying the issue or serving as change agents. This serves to facilitate intergenerational critical learning opportunities, engaging with marginalized perspectives and the opportunity for students to not only encounter narratives of hope but to begin to creatively imagine how they themselves can be part of a compassionate action response to their sustainability issues of concern. Finally the third learning space of the Future Leaders Programme is compassionate action, where students participate as knowledge creators and learn through collaboratively leading their own sustainability action projects. Students are encouraged to learn through trial and error, partnering with other change agencies wherever possible, but supported in risking being innovative as they discover new ways they can 
collectively change their world through civic action.

The Future Leaders Programme has to date worked with over 200 children and young people (aged between 7 and 19 years old) in a variety of settings including inner city, urban and rural locations. It has also involved working with young people from a wide range of socioeconomic backgrounds. The young people taking part have engaged in a broad range of sustainability issues, and as a result have imaginatively created numerous compassionate civic action responses. These have included the following:

- Pupils from a village primary school who identified as their sustainability issue of concern air pollution, and more specifically traffic pollution, in their locality. They enquired into how other schools had sought to make a positive difference to this issue. Their action response was to work with school staff and the student council to pilot a walking bus scheme, which resulted in a reduction of the number of car journeys parents were making to and from the school.

- Pupils from an inner city secondary school who recognised a pressing sustainability challenge to be threats to community cohesion, due to gang culture and racial division in their neighbourhood. They enquired into how their local council was tackling gang culture and developed a school wide global citizenship initiative to create artwork that celebrated the cultural diversity of the pupils in their school, under a unifying slogan of 'play your part, play it well'.

- A team of sixth form students who identified a sustainability issue of concern to be the loss of wisdom exchange through intergenerational relationship breakdown. Their enquiry involved researching the causes of this breakdown within a rapidly changing world, and the different perspectives of senior citizens living in a neighbouring sheltered housing area. Perceiving a contributing factor to be the lack of opportunities for the younger and older generations to meet and build friendships with each other, their action response was to organise a trip with a group of students and senior citizens to a ballroom in a nearby seaside resort. There the senior citizens were invited to teach the students how to ballroom dance, whilst reminiscing over what life was like when they were teenagers. In so doing, stronger and more convivial relationships for intergenerational learning between the two groups of people in that particular neighbourhood were instigated.

- A youth group who expressed mutual concern over social inequality and a sense of solidarity with children who lack of access to play due to poverty, homelessness and child labour practices. They enquired into the UN Convention of the Rights of the Child and explored positive responses through agencies working with street children nationally and internationally. Their action response was to develop a workshop for other young people that raised awareness of this issue and raised funds for play equipment to be bought by charitable organisations working with street children in Argentina, and youth at risk in their own town.

Initiatives such as the Future Leaders Programme highlight the challenging skill set and relational dexterity that any participatory, interdisciplinary and experiential pedagogical practice requires of both staff and students. It may also highlight the specific demands ESD places, such as sufficient knowledge of a broad range of sustainability issues and the social capital of connections to a range of relevant agents of sustainable change. This points towards the need for specific ESD staff development and training, and this is being increasingly identified and responded to at an international level (Sleurs 2008). This ESD practice has also highlighted the importance of longitudinal research into the educational outcomes for ESD participants. Whilst students might initially report a range of educational benefits such as the 
development of self-efficacy, communication skills, teamwork and greater cultural appreciation, questions over the extent and nature of longer-term impacts and benefits remain largely unanswered.

\section{Conclusion}

Education for Sustainable Development represents a global education reform movement that has as its fundamental aim learners developing the competencies required to contribute towards social justice and environmental stewardship goals. It encourages staff and students to work towards creating educational systems based upon an active concern for the wellbeing of all and upon a notion of civic compassion that acknowledges our relational interconnectivity across species, place and time. ESD represents a radically alternative vision of education that when pursued at a maximal level has implications for the curriculum, campus and culture of schooling.

With regard to putting ESD into teaching and learning practice, the monitoring and evaluation work that has stemmed from the UN Decade of ESD has highlighted a gradual shift in alignment of ESD towards more active and participatory pedagogical approaches (Tilbury 2011). Through the participatory learning process of conceptualising, planning, acting and reflecting it is argued that students are better able to engage holistically with the values, skills and knowledge areas for their sustainability competencies to be developed. The Future Leaders Programme represents but one example of ESD being put into practice in a way that has sought to broaden the participatory learning spaces students are served with. It has highlighted the power of children and young people as agents of change, when they are given the autonomy to critically and creatively pursue their own sustainable futures. Creating ESD learning spaces within current institutional architecture, curriculum constraints and community contexts is fraught with challenge, and this can certainly be helped by more specialist training. But despite these difficulties, the vision of a kinder and more caring world upon which ESD is founded asks educators to persevere and to not lose sight of the importance of empowering and mobilising children and young people through pedagogies of civic compassion in the $21^{\text {st }}$ Century.

\section{References}

Department for Children, Schools and Families (DCSF) (2008) s3:sustainable school selfevaluation: Driving school improvement through sustainable development. Nottingham: DCSF

Fielding, M. (2011) 'Patterns of partnership: Student Voice, intergenerational learning and democratic fellowship' in Mockler, N. \& Sachs, J. (Eds) Rethinking educational practice through reflexive inquiry. Netherlands: Springer.

Fielding, M. \& Moss, P. (2011) Radical Education and the Common School. London: Routledge.

Hart, R. (1997) Children's Participation. London: Earthscan.

IGES (2015) Achieving the Sustainable Development Goals: From Agenda to Action. Kanagawa: Institute for Global Environmental Strategies. 
Orr, D. (2011) Hope as an imperative: The essential David Orr. Washington: Island Press.

Orr, D. (1994) Earth in Mind: on education, environment and the human prospect. Washington: Island Press.

Peterson, A. \& Warwick, P. (2015) Global Learning and Education. Oxon: Routledge.

Rieckmann, M. (2011) 'Key Competencies for a Sustainable Development of the World Society: Results of a Delphi Study in Europe and Latin America' GAIA 20/1 (2011): 48-56

Sleurs, W. (Ed) (2008) Competencies for ESD teachers.

http://www.unece.org/fileadmin/DAM/env/esd/inf.meeting.docs/EGonInd/8mtg/CSCT\%20Handbook Extract.pdf

Sterling, S (2001) Sustainable Education: Re-visioning learning and change. Totnes: Green Books.

Sterling, S. (2005) Linking Thinking: New Perspectives on Thinking and Learning for Sustainability. Dunkeld: WWF Scotland.

Tilbury, D. (2011) Education for Sustainable Development: An Expert Review of Processes and Learning. Paris: UNESCO.

United Nations (2015) Sustainable Development Goals

https://sustainabledevelopment.un.org/?menu=1300

United Nations Educational, Scientific and Cultural Organisation (UNESCO) (2015)

Rethinking Education: Towards a global common good. Paris: UNESCO.

United Nations Educational, Scientific and Cultural Organisation (UNESCO) (2014)

Roadmap for implementing the global action programme on Education for Sustainable Development. Paris: UNESCO.

WCED (1987) Our Common Future: The Report of the Brundtland Commission. Oxford: Oxford University Press.

Zusman, E., Bengtsson, M. \& Holsberg Olsen, S. (2015) 'Governing the Sustainable Development Goals: Closing the gap between aspiration and action' in IGES (2015) Achieving the Sustainable Development Goals: From Agenda to Action. Kanagawa: Institute for Global Environmental Strategies. 